\title{
Field Drying of Cassava in a Solar Tent Dryer equipped with a Solar Chimney
}

\author{
J. K. Afriyie \\ Department of Mechanical \\ Engineering \\ Kumasi Polytechnic \\ P. O. Box KS 854, Kumasi, \\ Ghana
}

\author{
O-W. Achaw \\ Department of Chemical \\ Engineering \\ Kumasi Polytechnic \\ P. O. Box KS 854, Kumasi, \\ Ghana
}

\author{
K. A. Aikins \\ Department of Agricultural \\ Engineering, College of \\ Engineering \\ Kwame Nkrumah University \\ of Science and Technology \\ Kumasi, Ghana
}

\author{
C. K. K. Sekyere \\ Department of Mechanical and \\ Manufacturing Engineering \\ University of Energy and \\ Natural Resources \\ P. O. Box 214, Sunyani, Ghana
}

\author{
A. Bart-Plange \\ Department of Agricultural \\ Engineering, College of \\ Engineering \\ Kwame Nkrumah University \\ of Science and Technology \\ Kumasi, Ghana
}

\begin{abstract}
The performance of a solar tent dryer equipped with a solar chimney, as against that of open sun drying, was examined in the drying of cassava. An initial no-load trial was done, followed by trials with the dryer loaded with cassava. One drying trial was performed with the crops on the lower shelf, another with the crops on the upper shelf and a third trial with the dryer loaded on both the lower and upper shelves. In each drying trial, some cassava were also dried in the open sun which results were compared to that of the dryer. In the no-load process, the temperature inside the dryer increased with height due to thermo-syphon effects. But this trend was distorted by the evaporation of moisture from the crops during the drying processes, especially at the initial stages. About $75 \%$ to $80 \%$ of the drying process occurred within the first two days and nights of the drying periods. The open-sun drying was faster at the initial stages of drying, especially when the crops were on the lower shelf or the dryer was fully loaded. But the performance of the dryer overtook that of the open sun drying at later stages of drying. Thus, the dryer started more slowly but finished earlier than the open-sun drying. The best drying performance was observed when the crops were high up the dryer, though only a small amount of crops could be allowed at this height due to the design of the dryer.
\end{abstract}

Keywords: cassava; crop drying; solar chimney; natural ventilation

\section{INTRODUCTION}

About $65 \%$ of Ghana's workforce is made up of rural-based farmers (Owusu-Baah, 2004). Yet the food in the Ghanaian markets is generally not enough. This is partly caused by post-harvest losses, which is being compounded by increase in Ghana's population. The farmers need to dry their crops to enable them preserve and sell the crops at appropriate time in their prime marketable condition at remunerative prices. Crop drying helps in reducing the moisture content to a level below which deterioration does not occur and the product can be stored for a definite period (Sharma et al., 2009). As noted by Sharma et al. (2009) there has been very little penetration of solar drying technology. The farmers normally dry their crops by spreading them on mats in the open sun, sometimes even on bare ground by the road side (figure 1). This way of crop drying is not that efficient, and the crops are exposed to rain, pest, rodents and various forms of unhygienic conditions.

Crop drying is the removal of moisture from crop into the surrounding air. The drying process is enhanced whenever the vapour pressure of moisture in the crop is higher than the partial pressure of vapour in the air. The vapour pressure in the crop increases with increase of crop temperature. On the other hand, the vapour pressure in the air reduces as the relative humidity $(R H)$ of the air reduces, and this can be achieved by increasing the air temperature (Rogers and Mayhew, 1993; Jain and Tiwari, 2004). Thus crop drying becomes very effective when both the crop and the surrounding air are constantly warm. As the moisture escapes from the crop into the air, the air becomes more humid and needs to be replaced with less humid air for the drying process to proceed effectively. So a current of warm air is mostly required for effective drying process.

A crop dryer normally requires a heating device to preheat and reduce the relative humidity of the air en route to the crops in a drying chamber. There are two main types of crop dryers; the forced-convection (or forced-ventilation) and the natural-convection (or natural-ventilation) types. The forcedventilation dryer uses an electrically or a mechanically powered blower to blow the drying air through the crop. The natural-convection dryer depends on the natural buoyancy flow of air created by the thermo-syphon effect through the 
system. The use of electricity is too expensive for the farmers who live far away from the national electricity grid. The use of heating sources like wood may also be expensive or unfriendly to the environment. The afore-mentioned challenges can be avoided through the use of simple and cheap natural convection solar crop dryers to help generate income for the farmers, and meet the present and future demand for food in the community. These dryers are normally not too expensive to construct, and all the parts are locally available. Developing these dryers in the rural areas would also provide jobs for the artisans and youth in the rural areas and help to curb the rural-urban drift among the youth.

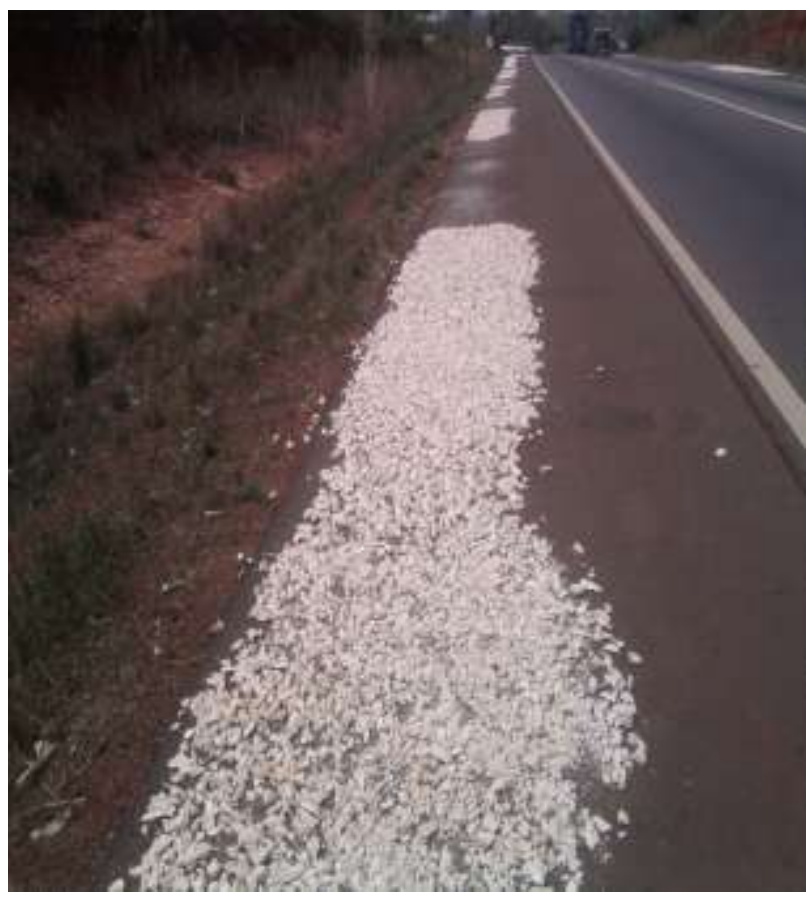

Figure 1 Open-sun drying of cassava on bare ground

Picture taken at Abofour in the Ofinso District in the Ashanti Region of Ghana

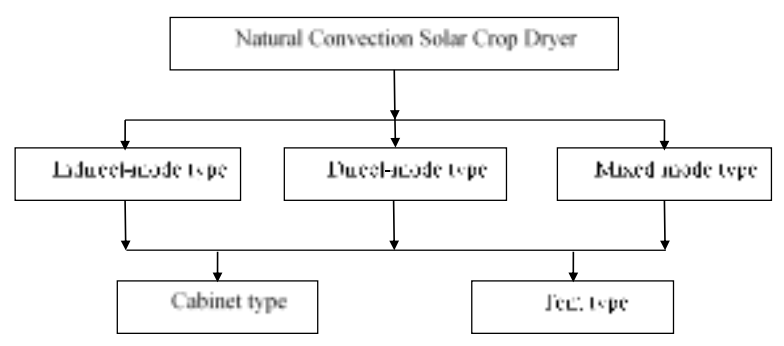

Figure 2 Types of natural convection solar crop dryers

As depicted in figure 2, a natural convection solar dryer is normally one of three kinds. The indirect-mode type is equipped with a preheating device to preheat the air before it encounters the crops in the drying chamber. The walls of the drying chamber are opaque so that the crops have no contact with sunlight. The direct-mode dryer has no air preheater, and the radiant energy passes through the transparent walls of the drying chamber whose content, including the crops, serve as the main absorber for heating the drying air. The mixed-mode dryer has an air preheating device and also transparent drying- chamber walls to allow maximum radiant energy utilisation. Earlier reports indicate that the direct-mode type is highly inefficient due to poor ventilation, leading to excessively high temperatures with high humidity in the drying chamber (Ekechukwu and Norton, 1997; Ekechukwu, 1999b). Unless the dryers are well designed, the crops at times end up partially cooked rather than properly dried. Singh et al. (2004) however report that the direct-mode dryer can be more efficient than the indirect-mode dryer, the only problem at times being the poor quality of the produce, especially those that are sensitive to sunlight. On the other hand, the directmode dryer is the least expensive and has the highest chance of patronage among farmers in the developing countries most of whom have low economic base and can only afford the direct-mode dryer.

Some reports on chimneys show that, properly designed solar chimneys can boost the flow of air through an enclosure (Chantawong et al., 2006; Chen et al., 2003; Ekechukwu, 1999a; Ferreira et al., 2008; Ong, 2003; Ong and Chow, 2003;). The use of a solar chimney was combined with the effect of an appropriately inclined roof of the drying chamber for the so-called tent-dryer effect and a suitable inlet-exit area ratio to improve the ventilation in the direct-mode dryer (Afriyie et al., 2009; Afriyie et al., 2011; Afriyie and BartPlange, 2012; Afriyie et al., 2013). The works were performed on a laboratory model of the dryer constructed to constitute on one half symmetry of a tent dryer, with a slanted roof only on one side. The current work has been performed in the field on a fully symmetrical tent dryer with slanted roof on both sides to ensure stability against the local winds.

Figure 3 shows a functional architecture of the tent dryer. In operation, radiant energy of short wavelength from the sun is transmitted through the transparent drying-chamber and chimney glazings to fall on the absorbers in the dryer. The absorbers, after absorbing this radiant energy, in turn emit heat energy of long wavelength which cannot pass through the glazing back into the atmosphere. This trapped energy heats up the air in the drying chamber and chimney. As explained in the earlier reports, cold air enters the dryer through the bottom inlet, gets heated up and dries the crops inside the chamber. The drying air, which becomes more humid after moisture absorption from the crops, enters the solar chimney where it is heated again to become less dense and is then driven upwards to exit through the top vent into the surroundings. This brings about a continuous flow where the cold, dense air is drawn in to displace the warm air through the dryer (Afriyie et al., 2009; Afriyie et al., 2011; Afriyie and Bart-Plange, 2012; Afriyie et al., 2013).

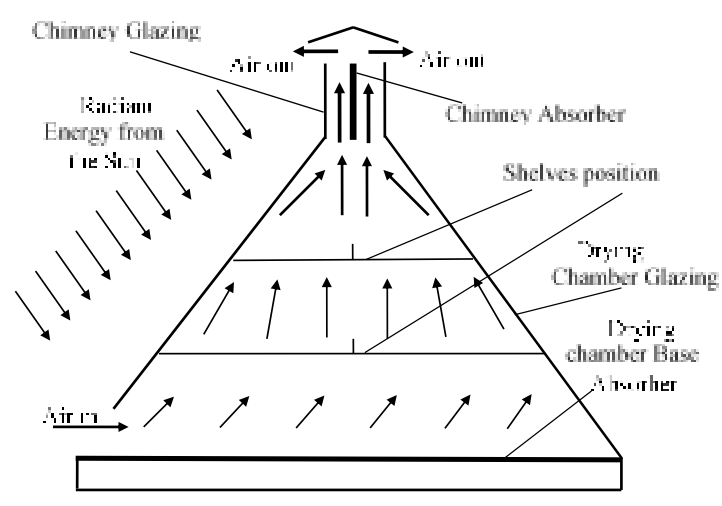


Figure 3 Functional architecture of the tent dryer equipped with a solar chimney

The test crop is cassava, a crop which is widely cultivated and harvested in the tropical and subtropical regions. It is a drought-tolerant, staple food crop which is increasingly becoming an important input in animal feed and human diet, processed in various ways in both the food and non-food industry (Olufayo and Ogunkunle, 1996; Pongsawatmanit et al., 2006; Cansee et al., 2008; Onyenwoke and Simonyan, 2014). It offers flexibility to resource-poor farmers because it serves as either subsistence or a cash crop (Stone, 2002).

Fresh cassava is, however, highly moisture laden, with high water quality. It therefore undergoes rapid postharvest deterioration, with a shelf life of the order of 24 to 48 hours after harvest (Andrew, 2002). Delayed processing of the cassava tubers will reduce the purity and functional properties of the starch produced from it (Lola et al., 2012). The high initial moisture content also makes it uneconomical to transport the fresh ones before drying. This brings about the need to dry the crop as close to the harvest point as possible, and the direct-mode dryer is most suitable for this. The objective of the current work is to investigate the performance of the fully triangular cross-sectioned solar tent dryer in the drying of cassava on the field, in relation to open-sun drying.

\section{MATERIALS AND METHODS}

\subsection{Experimental Set Up}

Using the results of works on the laboratory model, the solar tent dryer with its solar chimney was built to the dimensions shown in Appendix (Table A1). The dryer had a wooden framework. The wooden base of the drying chamber was covered with a steel sheet, painted black to act as radiant energy absorber. Along the base perimeter were beams of wood that extended downwards to limit the airflow and therefore the heat loss by convection underneath the base. The chimney absorber consisted of a sheet of steel, also covered with black paint, which run across the width of the dryer. The glazing of both the drying chamber and chimney was made of transparent glass sheet. The pictorial view of the dryer can be found in figure 4 .

Three clocks (SAKURA QUARTZ CLOCK), each with a hygrometer and a thermometer as integral unit, were positioned in the drying chamber to measure the relative humidity and temperature at various time intervals during the day. The measuring positions were $0.25 \mathrm{~m}$ above the base of the dryer, $0.40 \mathrm{~m}$ above the lower shelf (i.e. $0.75 \mathrm{~m}$ above the base) and $0.30 \mathrm{~m}$ above the upper shelf (or $1.35 \mathrm{~m}$ above the base). A fourth SAKURA unit was used outside to measure the relative humidity and temperature of the environment and the dryer inlet. The inlet data were taken in the middle of the dryer inlet (i.e. at $0.15 \mathrm{~m}$ above the base at inlet). A handheld liquid-in-glass thermometer was used to measure the chimney air temperature (at $1.85 \mathrm{~m}$ above the base). The liquid-in-glass thermometer was also used to check the thermometer readings on the SAKURA clocks for accuracy and consistency. There were two shelves for the drying crops, the lower and upper shelves, each with four trays of rectangular cross section. Each tray had mosquito net at the bottom to support the cassava, whilst allowing the air to flow through the system. The trays on the upper shelf were designated $\mathrm{H} 1, \mathrm{H} 2, \mathrm{H} 3$ and $\mathrm{H} 4$, whilst the lower shelf had L1, L2, L3 and L4 (figure 5). The length and width of each tray on the upper shelf were $0.69 \mathrm{~m}$ and $0.22 \mathrm{~m}$ respectively, whilst those of each tray on the lower shelf were $0.69 \mathrm{~m}$ and $0.45 \mathrm{~m}$ respectively.

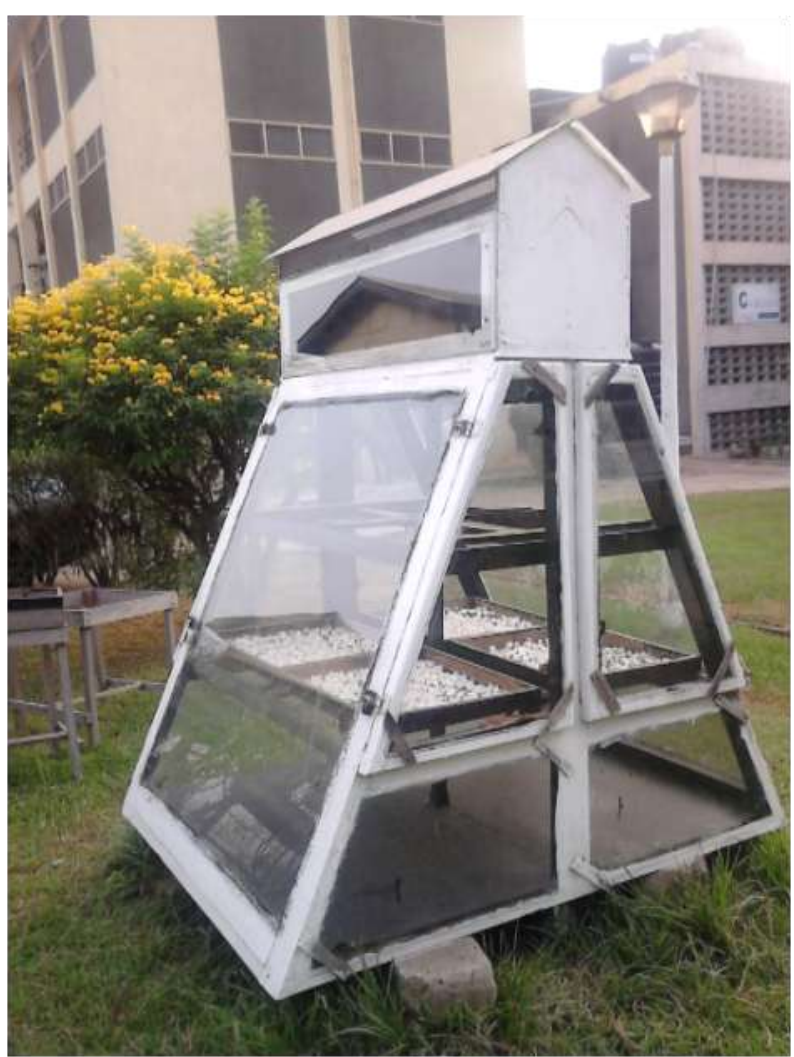

Figure 4 Pictorial view of a solar tent dryer equipped with a solar chimney

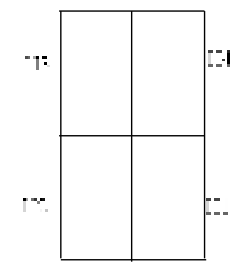

a) Trays arrangement on the upper shelf

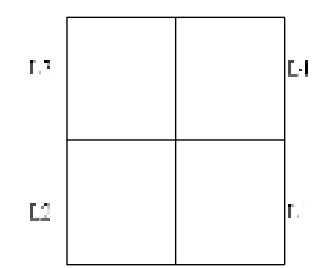

b) Trays arrangement on the lower shelf

Figure 5 Arrangements of drying trays on the shelves in the dryer

\subsection{Determining the Moisture Contents}

A sample of the crop was sent to a nearby Chemical Engineering Laboratory of Kumasi Polytechnic, Kumasi, Ghana, to determine the initial moisture content on wet basis $\left(M C_{\text {w.b. }}\right.$. An oven (wagtech; model GP-100-SLAD-250HYD) and a precision weighing scale (METTLER TOLEDO 


$$
\text { Initial } M C_{w . b .}=\frac{\text { Initial mass of sample }- \text { Final mass of sample }}{\text { Initial mass of sample }} \times 100 \%
$$

The dry solid mass of crop $m_{s}$ on each tray in the dryer was then determined from the initial $M C_{w . b .}$ as

$$
m_{s}=\frac{100-\text { InitialMC }_{\text {w.b. }}}{100} \times \text { Initialm }_{t}
$$

where $m_{t}$ is the total mass of crop (together with the moisture) on the tray. With the help of the solid mass $m_{s}$, the moisture content on dry basis $M C_{\text {d.b. }}$. on each tray at any instance of the drying process was determined from the total mass $m_{t}$ on the tray at that instance from the equation

$$
M C_{d . b .}=\frac{m_{t}-m_{s}}{m_{s}} \times 100 \%
$$

The $M C_{d . b .}$ was used for the calculations, as the denominator $m_{s}$ remained constant throughout the drying process. The conversion back to $M C_{w} . b$. was done through the equation

$$
M C_{\text {w.b. }}=\frac{100 M C_{d . b .}}{100+M C_{d . b .}}
$$

A mechanical kitchen weighing scale with a capacity of $5 \mathrm{~kg}$, whose accuracy was verified to two decimal places with the laboratory precision weighing scale (METTLER TOLEDO) indicated earlier, was used for determining the mass of crop in the field trials.

\subsection{The Trials}

A no-load trial was first performed on the dryer for a whole day without any crop in the dryer, in order to examine the temperature and relative humidity profile within and around the dryer. This was repeated for the next three days. The noload trial was followed by an under-load trial, with only the lower shelf loaded with trays of cassava (Trial UL1) for six days to allow the crop to dry appreciably. The dryer was then loaded only on the higher shelf for another under-load trial (Trial UL2) for six days. A third six-day under-load trial was later performed, with the dryer fully loaded on both the lower and upper shelves (Trial UL3). Each under-load trial also included the drying of some crops outside the dryer on three trays which were placed at the same level as the lower shelf but at different locations in the open sun. The open-sun drying served as control drying for its performance to be compared with the performance of the dryer under the same environmental conditions. The crops were cut into quadrants of average radius $0.03 \mathrm{~m}$ with average length $0.05 \mathrm{~m}$. The average loading density on each tray, both inside and outside the dryer, was $12.3 \mathrm{~kg} / \mathrm{m}^{2}$. The inlet of the dryer, as well as the top of the control trays, was covered in the night and when it rained, to prevent the sucking in of moisture at those periods.

Readings of relative humidity and temperature were taken at two-hourly intervals. The no-load trial on each day began at 08 hours in the morning and ended at 18 hours in the evening at local times. The first day of the under-load trial began at noon, after the crops had been prepared and cut to the required sizes. The crops were weighed at the beginning and end of each drying day.

\subsection{Data Analysis}

Analysis of variance (ANOVA) was performed on the data recorded, and the average mean was analysed by Duncan's test at $95 \%$ confidence level a $(\mathrm{p}<0.05)$. The statistical software used was SAS (SAS Institute Inc., Cary, NC, USA).

\section{RESULTS}

The temperature and also relative humidity of the environment and dryer inlet varied from morning till evening on each day of the experiments. To eliminate the effects of variations in the external conditions at various times of the trials, the temperature rise above ambient at various heights and the corresponding relative humidity difference in relation to the ambient conditions were used to analyse and compare the heating at various heights of the dryer. Figure 6 shows the mean temperature rise above ambient at various heights in the dryer and their corresponding mean relative humidity differences with the ambient conditions at various local times for the no-load trial. The highest temperatures above ambient, with the highest gradients, are generally observed for the local times 12 and 14 hours. This is followed by the local times 10 and 16 hours. Those temperature variations were found to be significant from the mean-comparison analyses with the SAS software. The extent of temperature variations and gradients, however, reduced for the local time 18 hours. At local time 08 hours, there was no significant increase of temperature with height, and the temperatures at the heights of 0.75 and $1.35 \mathrm{~m}$ (in the drying chamber) and at height $1.85 \mathrm{~m}$ (inside the chimney) were even slightly lower than the ambient temperature. The relative humidity variations at various positions, which were recorded only up to the top of drying chamber, showed an opposite trend to that of the temperature variations, decreasing as the air rose up the dryer, with the exception of the variation at local time 08 hours.

In figure $7 \mathrm{a}$, the temperature variations in the second drying day (the first full drying day from 08 hours to 18 hours) is used to represent the variations within the initial stages of drying whilst figure $7 \mathrm{~b}$ shows the variation at a later stage (the fourth drying day) of Trial UL1. On day 2 of Trial UL1 the temperature dropped in the local times 10,12 and 14 hours from the height $0.25 \mathrm{~m}$ to $0.75 \mathrm{~m}$, where the drying air passed through the crops on the lower shelf, before rising again in the top of drying chamber and in the chimney. In the local times 08 and 18 hours the temperatures generally fell as the air rose up the drying chamber (at height $1.35 \mathrm{~m}$ ) and chimney (height $1.85 \mathrm{~m}$ ). On day 4 , the temperature variations became more like those of the no-load trials in figure 6. In figure $8 \mathrm{a}$, the rise in temperature with height on day 2 was interrupted from height $0.75 \mathrm{~m}$ to $1.35 \mathrm{~m}$, as the air encountered the crops on the upper shelf, before the temperature rose again into the chimney. As indicated in figure $8 \mathrm{~b}$, the interruption in the temperature variation was less pronounced so that the trend on day 4 again tended to follow that of the no-load trial more closely. 
International Journal of Science and Engineering Applications

Volume 5 Issue 3, 2016, ISSN-2319-7560 (Online)

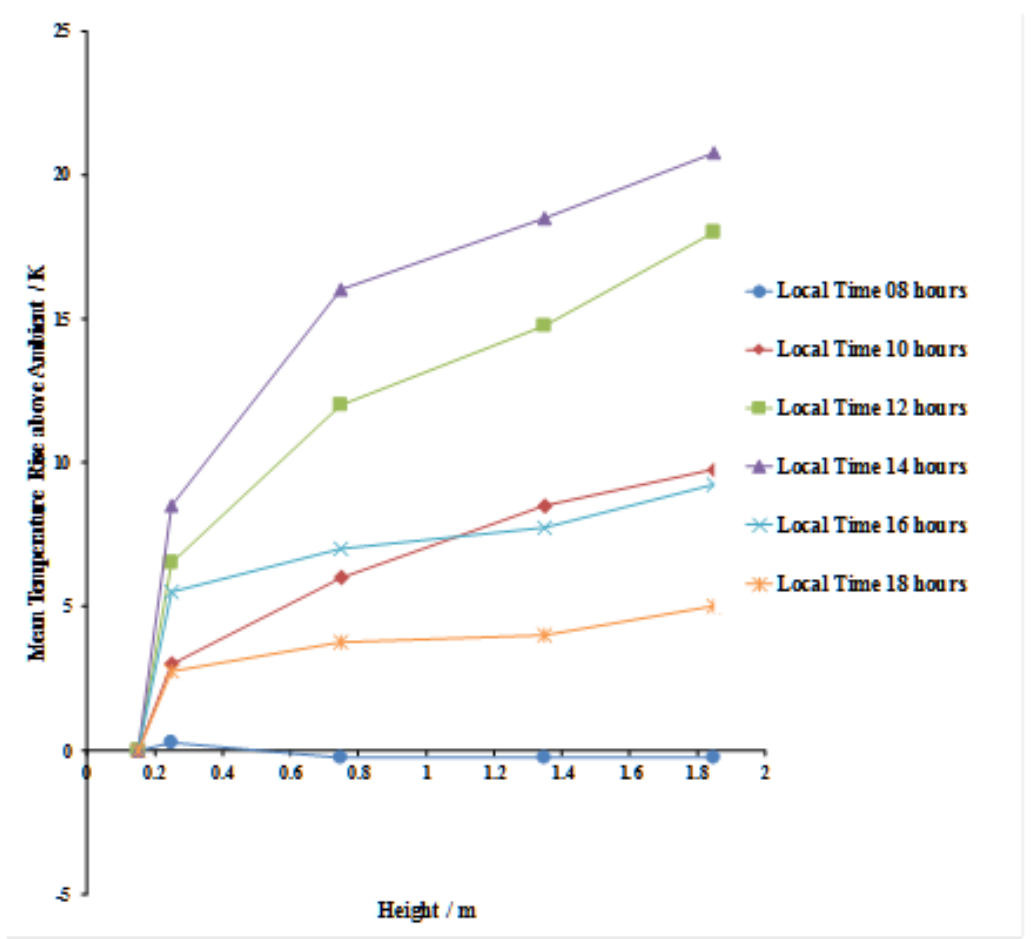

a) Mean Temperature Rise above Ambient vs Height

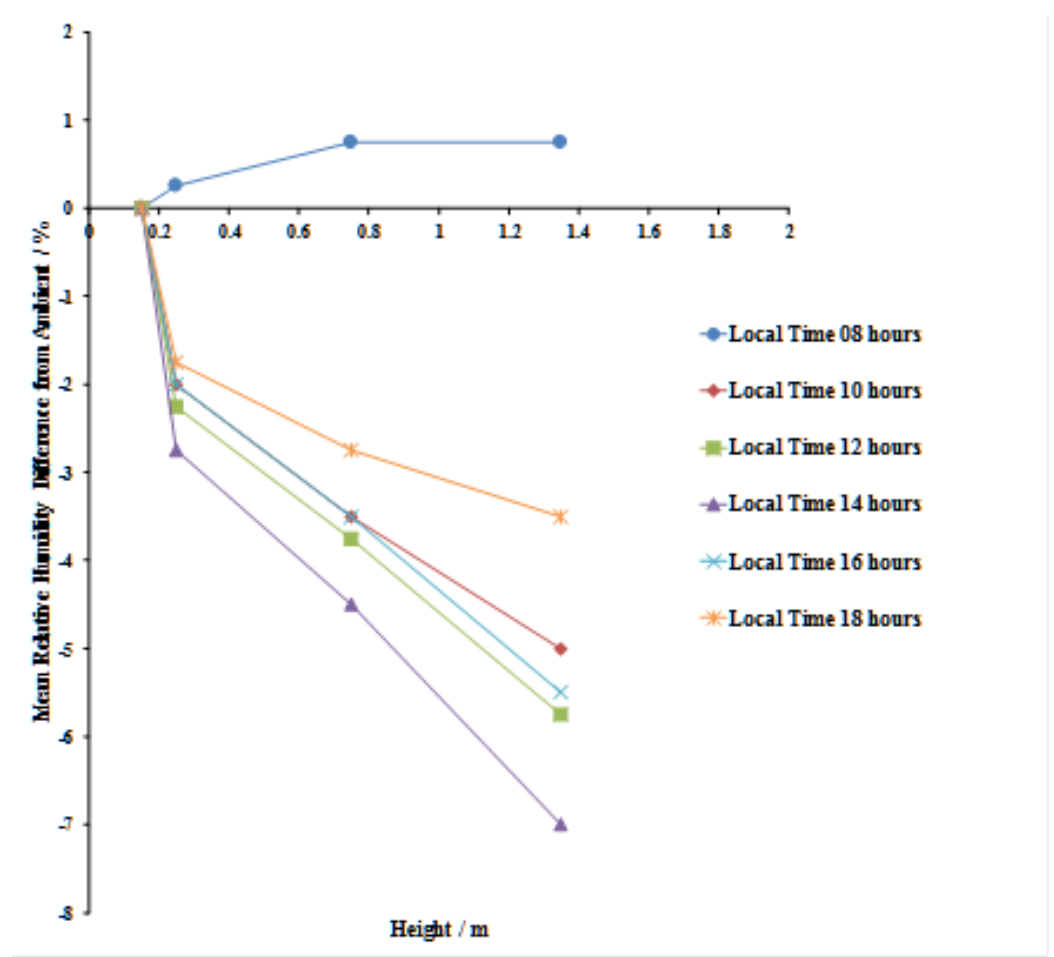

b) Mean Relative Humidity difference from Ambient vs Height

Figure 6 Variation of the mean temperature above ambient and the mean relative humidity difference from ambient with height inside the dryer for the no-load trial 


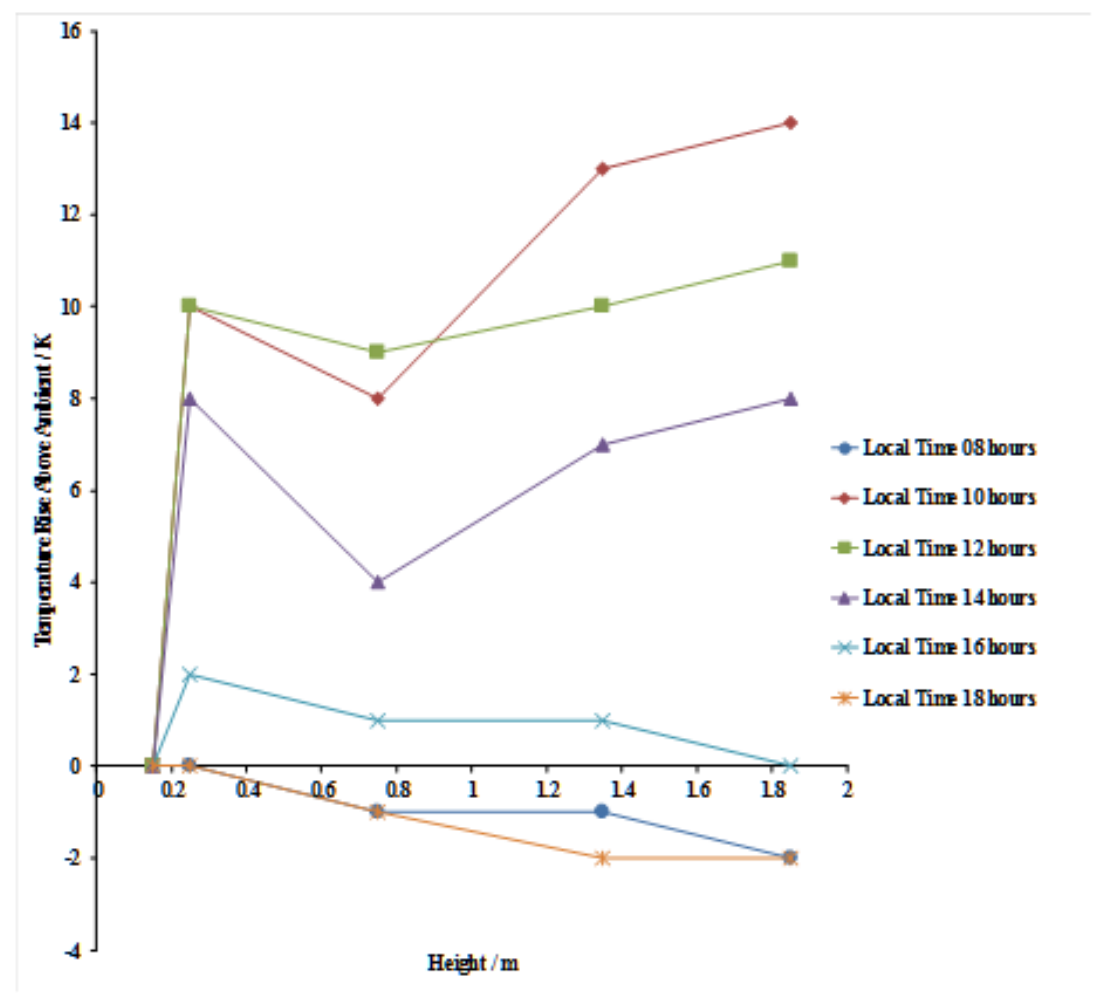

a) Temperature above Ambient vs height, Day 2

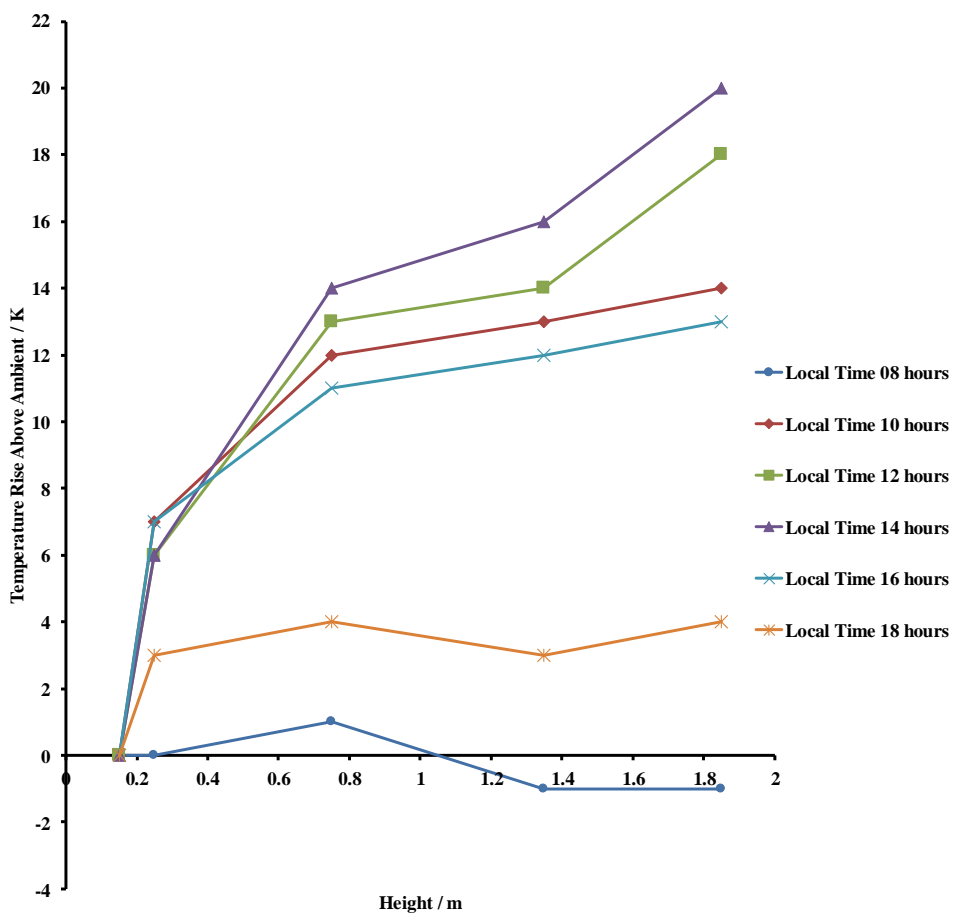

b) Temperature above Ambient vs height, Day 4

Figure 7 Variation of temperature above ambient with height inside the dryer for the Trial UL1: crops on the lower shelf 
International Journal of Science and Engineering Applications Volume 5 Issue 3, 2016, ISSN-2319-7560 (Online)

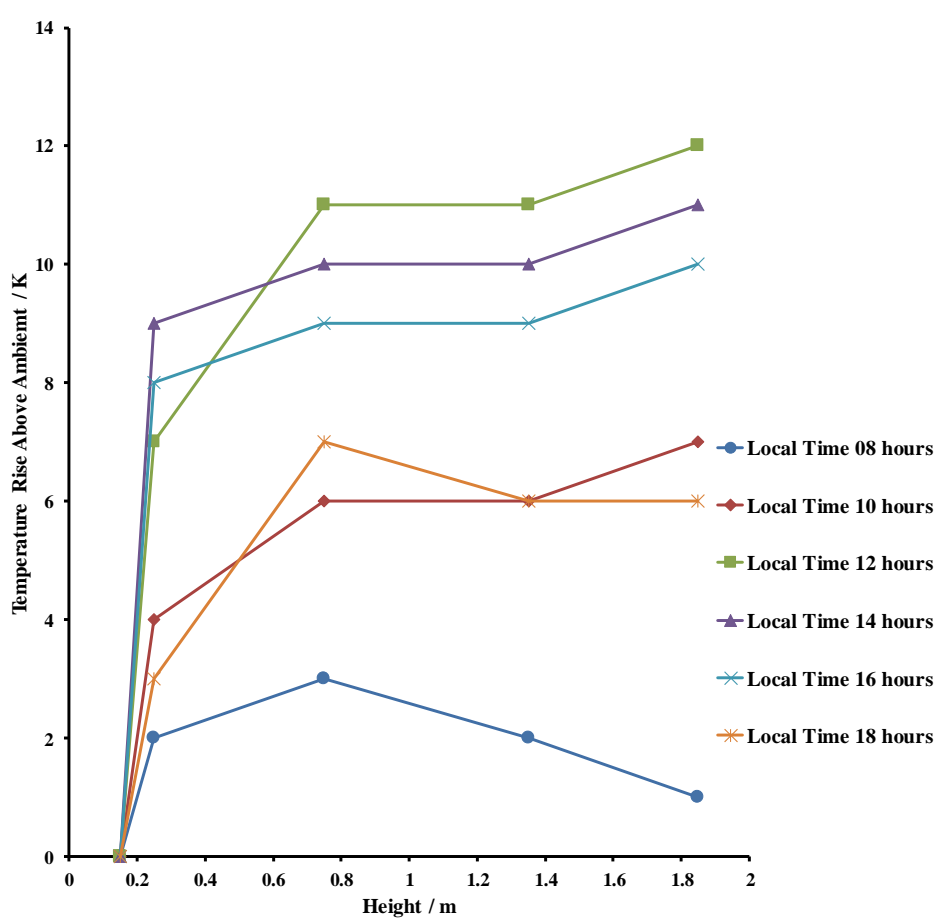

a) Temperature above Ambient vs height, Day 2

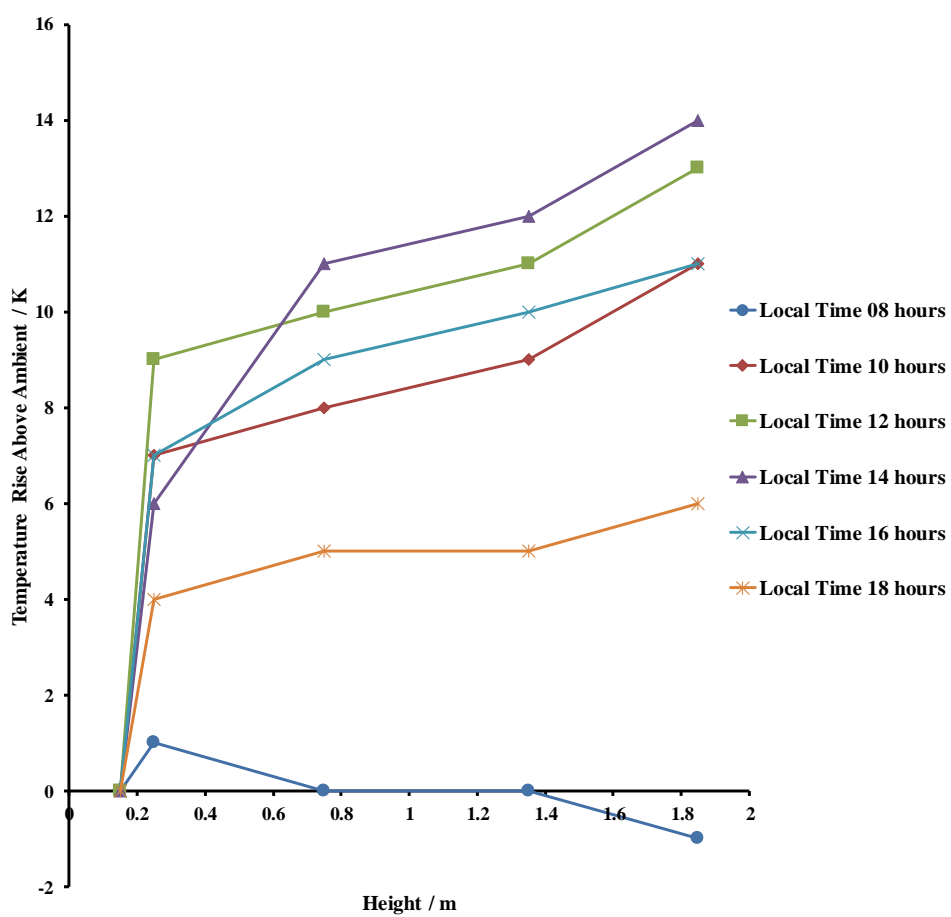

b) Temperature above Ambient vs height, Day 4

Figure 8 Variation of the temperature above ambient with height inside the dryer for the Trial UL2: crops on the upper shelf 


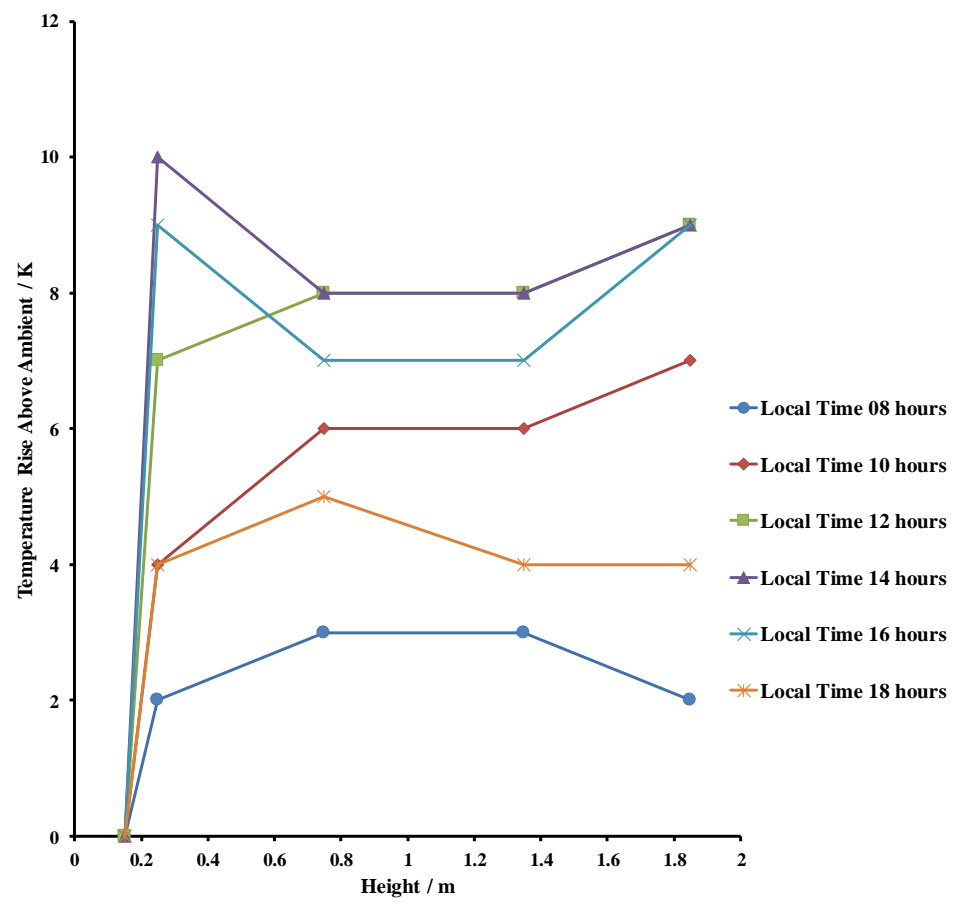

a) Temperature above Ambient vs height, Day 2

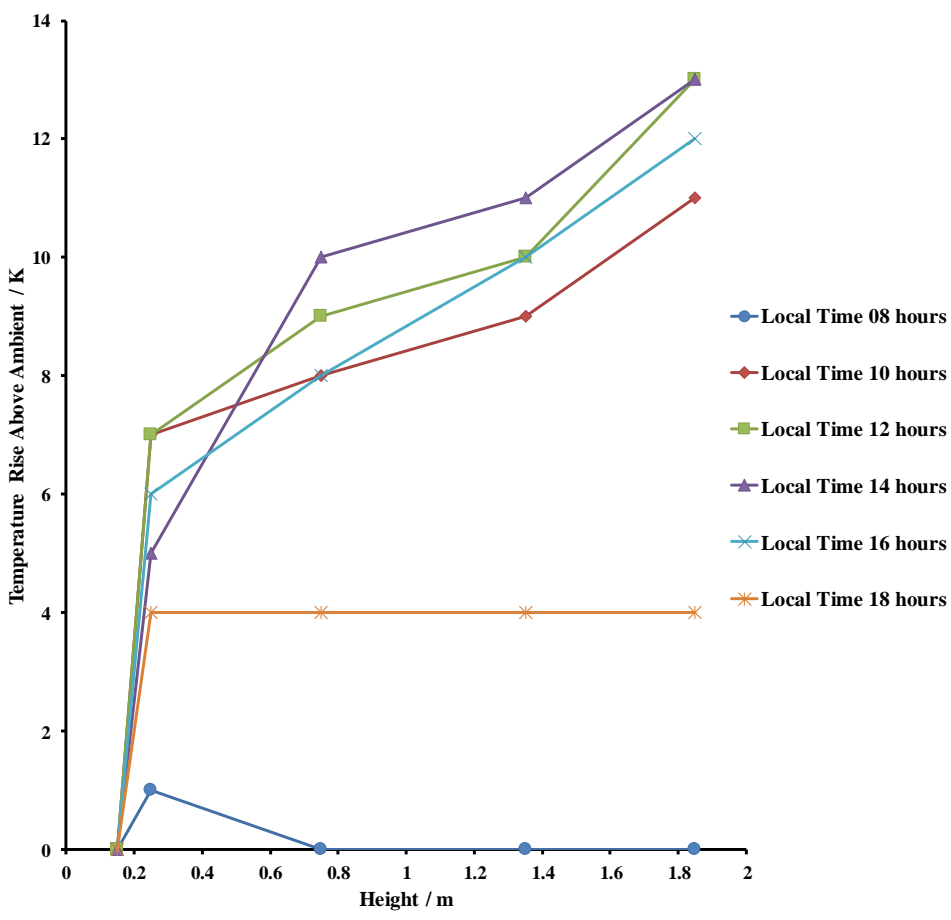

b) Temperature above Ambient vs height, Day 4

Figure 9 Variation of the temperature above ambient with height inside the dryer for the Trial UL3: dryer fully loaded 
With the dryer loaded on both the lower and upper shelves, the second-day temperature variation pattern in figure 9a was far more deviated from that of the no-load trial. The variation pattern on day 4, however, again followed similar trends to that of the no-load trial (figure 9b). In all the trials the temperatures inside the dryer were generally higher than the environment or inlet temperature (represented by height 0.15 $\mathrm{m}$ on the graphs) apart from few instances of local times 08 and 18 hours.

Figures 10 to 12 show the variation of moisture content on dry basis $\left(M C_{d . b}\right)$ of the crops on various days of the under-load trials. The drying time from 12 to 18 hours on the abscissa axis indicates the variations in the six-hour period of the first day; from 18 to 28 hours is for the ten-hour drying period (local times 08 to 18 hours) of the second day; 28 to 38 hours is for the third day; 38 to 48 hours, 48 to 58 hours and 58 to 68 hours are for the fourth, fifth and sixth days respectively. The vertical lines at times 18, 28, 38, 48, 58 and 68 hours show the $M C$ drop from the self-drying at various nights when the sun was not shining.

Starting from an initial moisture content on dry basis $(\mathrm{db})$ of $178 \%$ in Trial UL1 (figure 10), the crops on the control tray dried faster on the first day, with the mean $M C_{d b}$ dropping to $109 \%$, whilst the mean $M C_{d b}$ in the dryer got to $129 \%$. The ANOVA analyses with the SAS software showed a high significant difference between the two means. The cassava in the dryer became brownish by the end of the first day. By the end of day two, the mean $M C_{d b}$ in the dryer had fallen to $45 \%$, just below that of the control at 47\%. After overtaking that of the control, the drying process inside the dryer continued to be faster to end the third day with a mean $M C_{d b}$ of $19 \%$ whilst that of the control was at $32 \%$. By the end of the third day, the cassava in the open sun looked more brownish than that in the dryer. The mean $M C_{d b}$ values fell to around 6\% and $20 \%$ in the dryer and on the control tray respectively by the end of day five, and stayed around these values with no significant variation up to the end of day six. Most of the drying occurred within the first two days with the $M C_{d b}$ dropping from around $178 \%$ to $37 \%$, and from $178 \%$ to $42 \%$, for the dryer and control respectively, by the morning of day three (figure 10). As indicated by the vertical lines, most of the night drying also occurred within this period. The night drying from the fourth day on wards was not significant. In the graphs, the point for the previous night and the next morning are almost merging, so that the vertical lines are not that visible from the fourth day.

Starting with an initial $M C_{d b}$ of $186 \%$, d.b. in Trial UL2, the $M C_{d b}$ dropped to $126 \%$ in the dryer whilst that of the control dropped to $123 \%$ on day one (figure 11). The crops in the dryer again looked brownish whilst those in the open sun still looked whitish after the first day. By the morning of the second day both moisture content values had dropped to around $116 \%$ with no significant difference. On the second day, drying was faster in the dryer, ending the day with $M C_{d b}$ $45 \%$, whilst that of the control was $59 \%$. The gap in $M C_{d b}$ between the crop in the dryer and that of the control tray continued to be wider (as compared to that in Trial UL1) up to the end of the fifth day when the value in the dryer got to around 6\% and remained around this figure up to the end of the sixth day with no significant variation. The $M C_{d b}$ of the control crop was around $25 \%$ at the end of day five, and this fell further to around $20 \%$ by the end of day six. The crop in the open sun again appeared more brownish than that in the dryer by the end of day three. Like the results in Trial UL1, most of the drying occurred within the first two days and nights, with the $M C_{d b}$ dropping from $186 \%$ to $42 \%$ and from $186 \%$ to $55 \%$ for the dryer and control tray respectively by the morning of the third day.

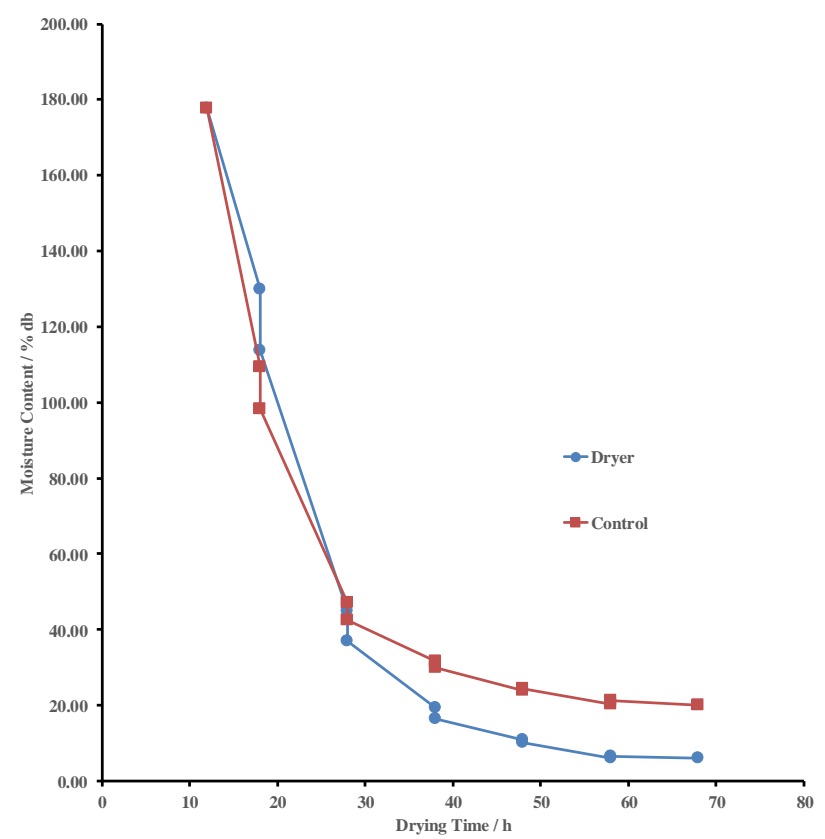

Figure $10 \quad$ Variation of Moisture Content on dry basis with Time for Trial UL1; crops on the lower shelf only 


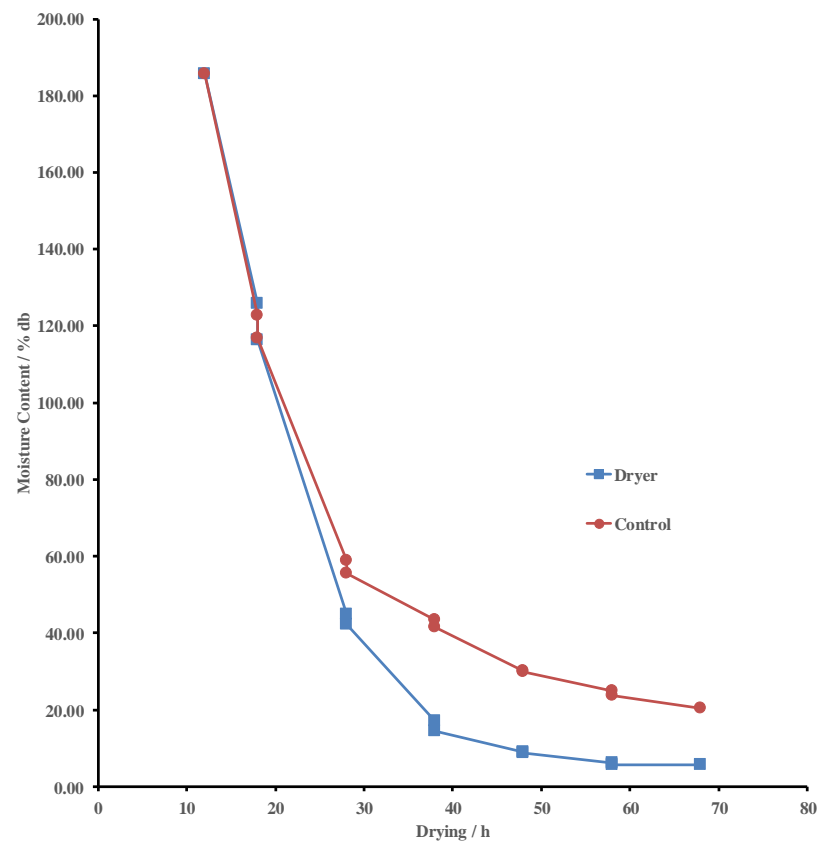

Figure 11

Variation of Moisture Content on dry basis with Time for Trial UL2; crops on the upper shelf only

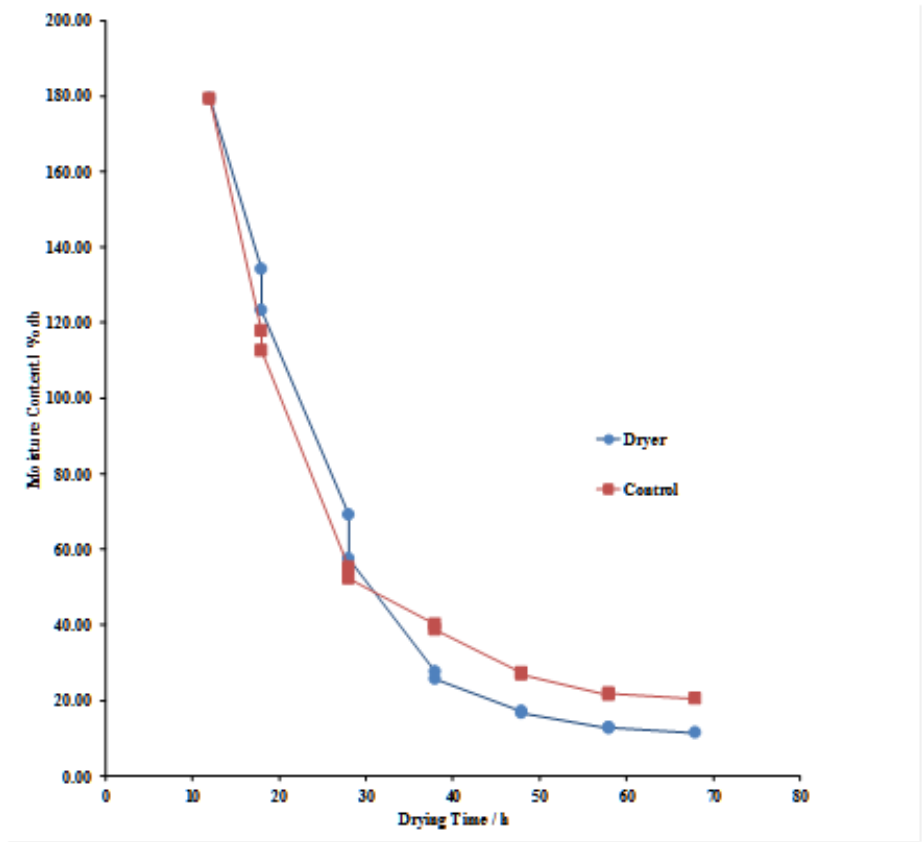

Figure 12

Variation of Moisture Content on dry basis with Time for Trial UL3; dryer at full load

In Trial UL3, the control crops dried faster than the crops in the dryer during the first two days (figure 12). The drops in $M C_{d b}$ were from $179 \%$ to $55 \%$ and $179 \%$ to $52 \%$ for the dryer and control tray respectively. The drying performance of the dryer overtook that of the control tray during the third day and continued to dry faster than the control till the end of the sixth day. The dryer ended the sixth day with $M C_{d b}$ of $11 \%$, whilst that of the control tray was at $21 \%$. As in the case of the first two trials, the cassava in the dryer appeared brownish whilst that on the control trays still looked whitish after the first day, but the control cassava became more brownish from day three onwards. The gap in $M C_{d b}$ between the dryer and control tray from the third day onwards was closer than those of trials UL1 and UL2. Again as shown in figure 12, a high proportion of the drying process took place within the first two days and nights, like the first two trials.

\section{DISCUSSIONS}

The increase in temperature with height observed in the noload trial in figure 8a during the local times 10,12 and 14 hours is attributable to air heating inside the dryer from the intense radiant energy from the sun at those local times. The 
whole system then functioned as a heated chimney. In a heated chimney the air heating process induces a buoyancy flow of air up the dryer with a thermo-syphon effect in which the warm, less dense air is displaced upwards by cold, denser air from outside so that the lower part of the chimney remains colder than the upper part (Incropera et al., 2007).

The margin of temperature increase reduced around the local time 16 to 18 hours. This is attributable to the low energy intensity as the sun set at that time. In the morning around 08 hours the intensity was very low and the whole system functioned like a normal chimney in which the temperature fell as the air rose up the unheated chimney, as noted by Ekechukwu and Norton (1997) and also observed by Afriyie et al. (2009). The fall in relative humidity $(R H)$ at various heights where the temperature rose could be attributed to the fact the absolute humidity of air inside the dryer remained constant during the no-load trial. This constant absolute humidity meant that the $R H$ should fall as the temperature rose. The $R H$ for the local time 08 hours then showed an upward trend in response to the temperature which showed a downward trend (figure 6).

The interruption to the thermo-syphon induced upwards temperature gradient, as the air passed through the lower shelf (positioned between the heights $0.25 \mathrm{~m}$ and $0.75 \mathrm{~m}$ ) in the Trial UL1 may be attributed to the fact that part of the available energy was used for moisture removal from the crop. So the air temperature fell or did not increase any significantly during the air passage through the crops on the lower shelf at the initial stages, as indicated on the second day of drying in figure $7 \mathrm{a}$, during which most of the drying occurred (figure 10). Similarly, the interruptions to the thermos-syphon effects that occurred as the drying air moved across the higher shelf from the heights $0.75 \mathrm{~m}$ to $1.35 \mathrm{~m}$ in Trial UL2 (figure 8a) and across the lower and upper shelves from $0.25 \mathrm{~m}$ to $0.75 \mathrm{~m}$ and from $0.75 \mathrm{~m}$ to $1.35 \mathrm{~m}$ respectively in Trial $U L 3$ (figure 9a) are attributable to the use of part of the energy for moisture evaporation in addition to air heating.

During the later stages of drying the temperature gradient in all the under-load trials, as shown in figures $7 \mathrm{~b}, 8 \mathrm{~b}$ and $9 \mathrm{~b}$, tended to approach that of the no-load trials (figure 6a). This could be attributed to the slowdown of the drying processes at this stage of relatively low $M C$, as shown in figures 10,11 , and 12 .

During the initial stages of drying, the control tray (in the open sun) dried faster than the dryer, especially when the crops were loaded on the lower shelf or when the dryer was at full load. Similar results were observed by Jain and Tiwari (2004). The total energy for moisture removal from the crop, at any given temperature and pressure, is the sum of the latent heat of vaporisation and the binding energy of the moisture in the crop. As noted by Mujumdar (1997) the binding energy can be negative for starches at low temperatures. Eighty percent of carbohydrate produced in cassava is made up of starch (Onyenwoke and Simonyan, 2014). This means that the energy of moisture removal from a starchy crop like cassava, under atmospheric conditions, can be lower than the heat of vaporisation of water in the initial stages of drying especially when the $M C$ is high. This is further supported by Aviara and Ajibola (2002) that the heat of vaporization is low at high moisture contents. Normal local winds can therefore do a good job in removing large amounts of the unbound and free moisture from the crop in the initial stages of drying when the initial moisture content is high (Ekechukwu, 1999a; Okos et al., 1992).
At later stages of drying, the moisture becomes more strongly bound to the crop so that more air heating, rather than airflow, is required to remove this bound moisture from the crop. With more heating inside the dryer than outside, the dryer then performed better and overtook the performance in the open sun at later stages of drying. The night self-drying processes were caused by heat inertial effects where some energy stored in the system at periods of sunshine was used in the night for drying. The substantial proportions (about $75 \%$ to $80 \%$ ) of the drying processes that occurred within the first two days and nights for both inside the dryer and in the open sun are also attributable to the ease of moisture removal at high $M C$.

The best overall drying performance of the dryer in relation to that of open sun was observed in trial $U L 2$ in which the crops were high up the dryer. At this height, the shading effect of the crop shelf was much reduced so that there was a high view factor between the drying-chamber base absorber and the atmospheric dome around the dryer. This enhanced the radiant energy absorption at the base and a subsequent effective air heating of the drying air en-route to the crops. Further, the slant side of the dryer allowed a smaller quantity of crops at this higher level than that at the lower level for about the same quantity drying air which is more effectively heated. This tends to provide a solution to the challenge of ineffective air heating in the direct-mode dryer observed by Afriyie et al. (2009). The relatively poorest drying performance observed in UL3 is attributable to the increased quantity of crops to be dried by practically the same amount of heated air, although the dryer still performed better in the end than the open-sun drying.

The browning of the crop inside the dryer at the initial stages may be attributed to non-enzymatic activity caused by the level of water activity at that time. The water activity of crop increases with high $M C$ and also with high temperature (Mujumdar, 1997; Okos et al., 1992; Belessiotis and Delyannis, 2011). Higher temperature inside the dryer than outside, together with high moisture, caused fast browning of the crop in the dryer at the initial stages. At later stages, there was still a considerable amount of moisture in the crop being dried in the open sun, and this continued to cause discoloration so that those crops became more brownish than those inside the dryer.

\section{CONCLUSION}

A full solar tent equipped with a solar chimney was used to dry cassava and the drying performance was compared with that of open-sun drying. During daytime the whole system functioned as solar heated chimney, so that there was an upward temperature gradient with height which resulted in a downward gradient of the relative humidity, in the no-load process. Early in the morning, a period of low radiant energy intensity, the system functioned like a normal chimney with negative temperature gradient up the chimney. In the initial stages of the drying process, the daytime no-load temperature gradient was distorted as the available energy had to be shared between the drying process and the air heating process.

Drying still continued after sunset as a result of the heat inertial of the system. About $75 \%$ to $80 \%$ of the drying process occurred within the first two days and nights of the whole period for both the dryer and open-sun drying. The open-sun drying generally did better than the dryer at the initial stages, when cassava drying required more airflow than air heating. Further, high temperatures and lack of effective airflow in the dryer caused browning of the cassava at the 
initial stages. The dryer performance, however, overtook that of the open-sun drying at later stages, even at full load. The best performance of the dryer was when the crops were high up the dryer, but only a small amount of crops could be allowed at this height due to the slant sides of the dryer. To enhance the drying process and prevent browning of the crops within the first two days of the drying process, the side doors of the dryer could be opened and covered with only mosquito nets to allow the dryer to make effective use of the airflow from the local winds, while, at the same time, keeping insects and rodents at bay. The side doors could then be closed from the third day onwards to make use of the high temperature for further drying improvement. It can therefore be concluded that in addition to the fact that it is more hygienic, the structurally stable full tent dryer equipped with a solar chimney can end up with a much smaller moisture content of cassava than the moisture content from drying in the opensun.

\section{APPENDIX}

\section{Table A1 Dimensions of the solar tent dryer equipped with a solar chimney}

\begin{tabular}{ll}
\hline Part of dryer & Dimension \\
\hline Width of drying chamber base (perpendicular to inlet airflow) & $1.50 \mathrm{~m}$ \\
Length of drying chamber base (in the direction of inlet airflow) & $1.70 \mathrm{~m}$ \\
Height of drying chamber & $1.50 \mathrm{~m}$ \\
Thickness of drying chamber base & $0.03 \mathrm{~m}$ \\
Roof angle of drying chamber to the horizontal plane & $60^{0}$ \\
Dryer inlet width & $120 \mathrm{~cm}$ \\
Dryer inlet gap & $0.30 \mathrm{~m}$ \\
Height of chimney walls (glazed) & $0.48 \mathrm{~m}$ \\
Height of chimney roof (glazed) & $0.20 \mathrm{~m}$ \\
Height of chimney absorber & $0.48 \mathrm{~m}$ \\
Chimney gap & $0.40 \mathrm{~m}$ \\
Chimney roof angle to the horizontal & $38^{0}$ \\
Exit gap & $0.06 \mathrm{~m}$ \\
Height of lower shelf from the base of drying chamber & $0.35 \mathrm{~m}$ \\
Height of upper shelf from the base of drying chamber & $1.05 \mathrm{~m}$ \\
\hline
\end{tabular}

\section{ACKNOWLEDGEMENT}

The authors would like to express their sincere thanks to the Departments of Chemical Engineering and Mechanical Engineering of Kumasi Polytechnic, Kumasi, Ghana, for the use of their equipment and facilities. Further appreciations are expressed to the Kumasi Polytechnic as a whole for the use of its premises for the physical experimentations.

\section{REFERENCES}

Afriyie, J. K., Nazha, M. A. A., Rajakaruna, H. and Forson, F. K. (2009). Experimental investigations of a chimneydependent Solar Crop Dryer. Renewable Energy 34 (1), 217 222.

Afriyie, J. K., Nazha, M. A. A., Rajakaruna, H. and Forson, F.K., (2011). Simulation and optimisation of the ventilation in a chimney-dependent Solar Crop Dryer. Solar Energy 85, 1560-1573.

Afriyie, J. K. and Bart-Plange, A. (2012). Performance Investigation of a chimney-dependent Solar Crop Dryer for different inlet areas with a fixed outlet area. International Scholarly Research Network ISRN Renewable Energy, Article ID 194359, 9 pages doi:10.5402/2012/194359
Afriyie, J. K., Nazha, M. A. A., Rajakaruna, H. and Forson, F. K. (2013). Mathematical modelling and validation of the drying process in a chimney-dependent Solar Crop Dryer. Energy Conversion and Management 67, 103-116.

Andrew W. (2002). Cassava utilization, storage, and small scale processing. Natural resource institute, Chatham maritime. UK, 14, 270-290.

Belessiotis V. and Delyannis E. (2011). Solar drying. Solar Energy 85, 1665-1691

Cansee, S., Watyotha, C., Thivavarnvongs, T., Uriyapongson, J. and Varith, J. (2008). Effects of temperature and concentration on thermal properties of cassava starch solutions. Songklanakarin J. Sci. Technol. 30 (3), 405-411

Chantawong, P., Hirunlabh, J., Zeghmati, B., Khedari, J., Teekasap, S. and Win, M. M. (2006). Investigation on thermal performance of glazed solar chimney walls. Solar Energy 80, 288-297. 
Chen, Z. D., Bandopadhayay, P., Halldorsson, J., Byrjalsen, C., Heiselberg, P. and Li, Y. (2003). An experimental investigation of a solar chimney model with uniform wall heat flux. Building and Environment, 38, 893-906.

Ekechukwu O. V. (1999a). Review of solar-energy drying systems I: an overview of drying principles and theory. Energy Conversion and Management, 40, 593-613.

Ekechukwu, O. V. (1999b). Review of solar-energy drying systems II: an overview of solar drying technology. Energy Conversion and Management, 40, 616-655.

Ekechukwu, O. V. and Norton, B. (1997). Design and measured performance of a solar chimney for natural circulation solar energy dryers. Renewable Energy, 10 (4), 81-90.

Ferreira, A. G., Maia, C. B., Cortez, M. F. B., and Valle, R. M. (2008). Technical feasibility assessment of a solar chimney for food drying. Solar Energy 82, 198-205.

Incropera F. P., De Witt D. P., Bergman T. L. and Lavine, A. S. (2007). Introduction to heat transfer, 5th edition, John Wiley \& Sons Inc., Hoboken, New Jersey.

Jain, D. and Tiwari, G. N. (2004). Effect of greenhouse on crop drying under natural and forced convection I: Evaluation of convective mass transfer coefficient. Energy Conversion and Management, 45, 765-783.

Lola, A., Lawrence, O. O. and Adefunke, B. (2012). Effect of delayed processing on some physico-chemical properties of cassava starch. American Journal of Food and Nutrition Print; ISSN 2157-0167, Online: ISSN 2157-1317, doi:10.5251/ajfn.2012.2.2.31.36 @ 2012, ScienceHuß, http://www.scihub.org/AJFN

Mujumdar, A. S. (1997). Drying fundamentals. In: Baker, C. G. J. (Editor) Industrial Drying of foods, Blackie Academy and Professional, ISBN 0-7514-0384-9, 7-30.
Olufayo, A. A. and Ogunkunle, O. J. (1996). Natural drying of cassava chips in the humid zone of Nigeria. Bioresource Technology, 58, 89-91.

Ong, K. S. (2003). A mathematical model of a solar chimney. Renewable Energy 28, 1047-1060.

Ong, K. S. and Chow, C.C. (2003). Performance of a solar chimney. Solar Energy, 74, 1-17.

Onyenwoke, C. A. and Simonyan, K. J. (2014). Cassava postharvest processing and storage in Nigeria: A review. African Journal of Agricultural Research, 9 (53) 3853-3863.

Okos, M. R., Narsimhan G., Singh R. K. and Weitnauer, A. C. (1992). Food Dehydration. In: Heldman, D. R., Lund D. B., (Editors) Handbook of Food Engineering. Marcel Dekker, Inc, New York, Basel, Hong Kong, 437-562

Owusu-Baah K, Workshop on ECOWAS policy (2004).

(Accessed from the Ghana Homepage: http://www.ghaweb.com on 30/11/2004)

Pongsawatmanit, R., Temsiripong, T., Ikeda, S. and Nishinari, K. (2006). Influence of tamarind seed xyloglucan on rheological properties and thermal stability of tapioca starch. Journal of Food Engineering. 77 (1), 41-50.

Rogers, G. F. C. and Mayhew, Y. R. (1992). Engineering Thermodynamics, Work and Heat Transfer, 4th Edition, ISBN 0-582-04566-5

Sharma, A., Chen, C. R. and Lan, N. V. (2009). Solar-energy drying systems: A review. Renewable and Sustainable Energy Reviews 13, 1185-1210

Singh, S., Singh, P. P., Dhaliwal, S. S. (2004). Multi-shelf portable dryer. Renewable Energy, 29, 753-765.

Stone, G.D., 2002. Both Sides Now. Current Anthropology 43(4):611-630. 
International Journal of Science and Engineering Applications Volume 5 Issue 3, 2016, ISSN-2319-7560 (Online) 